\title{
Photocatalytic Activity of Diverse Organic Radical Anions: Catalyst Discovery Enables Cleavage of Strong C(sp2)-N and C(sp2)-O Bonds
}

Colleen Chernowsky, Alyah Chmiel, Zachary Wickens

Submitted date: 01/06/2021 - Posted date: 02/06/2021

Licence: CC BY-NC-ND 4.0

Citation information: Chernowsky, Colleen; Chmiel, Alyah; Wickens, Zachary (2021): Photocatalytic Activity of Diverse Organic Radical Anions: Catalyst Discovery Enables Cleavage of Strong C(sp2)-N and C(sp2)-O Bonds. ChemRxiv. Preprint. https://doi.org/10.26434/chemrxiv.14710398.v1

Herein, we leverage electrochemistry to examine the photocatalytic activity of a range of structurally diverse persistent radical anions and find that many are effective electrophotocatalysts. These studies uncover a new electron-primed photoredox catalyst capable of promoting the reductive cleavage of strong $\mathrm{C}(\mathrm{sp} 2)-\mathrm{N}$ and $\mathrm{C}$ (sp2)-O bonds even when reduction potentials hundreds of $\mathrm{mV}$ more negative than $\mathrm{Li} 0$ are required. We illustrated several examples of the synthetic utility of these deeply reducing but otherwise safe and mild catalytic conditions. Finally, we employed electrochemical current measurements to perform a reaction progress kinetic analysis that revealed that the improved activity of this new catalyst was a consequence of an enhanced stability profile.

File list (2)

Photocatalytic activity of diverse organic radical anions-rxi... (1.53 MiB) view on ChemRxiv • download file TOC graphic.jpeg (76.34 KiB) view on ChemRxiv • download file 


\title{
Photocatalytic activity of diverse organic radical anions: Catalyst discovery enables cleavage of strong $\mathrm{C}\left(\mathrm{sp}^{2}\right)-\mathrm{N}$ and $\mathrm{C}\left(\mathrm{sp}^{2}\right)-\mathrm{O}$
} bonds

\author{
Colleen P. Chernowsky, Alyah F. Chmiel, and Zachary K. Wickens*
}

\begin{abstract}
Herein, we leverage electrochemistry to examine the photocatalytic activity of a range of structurally diverse persistent radical anions and find that many are effective electrophotocatalysts. These studies uncover a new electron-primed photoredox catalyst capable of promoting the reductive cleavage of strong $\mathrm{C}(\mathrm{sp} 2)-\mathrm{N}$ and $\mathrm{C}(\mathrm{sp} 2)-\mathrm{O}$ bonds even when reduction potentials hundreds of $\mathrm{mV}$ more negative than Li0 are required. We illustrated several examples of the synthetic utility of these deeply reducing but otherwise safe and mild catalytic conditions. Finally, we employed electrochemical current measurements to perform a reaction progress kinetic analysis that revealed that the improved activity of this new catalyst was a consequence of an enhanced stability profile.
\end{abstract}

Reductive activation of organic molecules through single electron transfer (SET) is a fundamental elementary step at the heart of a myriad of synthetically useful transformations. ${ }^{[1-4]}$ In recent years, photoredox catalysis has emerged as a mild and chemoselective method to induce redox events. ${ }^{[5-10]}$ Unfortunately, while $400 \mathrm{~nm}$ light possesses sufficient energy for a maximum driving force of $3.1 \mathrm{eV}$, this energy is diminished by $25-50 \%$ through vibrational relaxation, internal conversion, and intersystem crossing. ${ }^{[11]}$ As a consequence, many abundant but thermodynamically stable molecules remain inert to photoredox activation. ${ }^{[12],[13]}$ Indeed, for over a century, alkali metals have remained reductants of unparalleled potency. These reagents continue to be used in both academic ${ }^{[14,15]}$ and industrial[16] settings despite their implicit hazards, poor chemoselectivity, and inextricable chemical waste. To address this, the development of new strategies to deliver extreme reduction potentials (significantly more negative than $-2 \mathrm{~V} v s$ SCE) with the safety and chemoselectivity profile of photoredox catalysis is an emerging area of considerable contemporary interest. ${ }^{[11,17-23]}$

Over the past several years, numerous groups, ${ }^{[24-27]}$ including ours, ${ }^{[27]}$ have begun exploring strategies to leverage mildly reducing radical species as a new family of photocatalysts that offer potentials on par with alkali metals (Figure 1, top). We have dubbed these reductively activated species electron-primed photoredox catalysts to distinguish them from more conventional photoredox catalyst designs. Pioneering work from König used a consecutive photoinduced electron transfer (conPET) approach to photochemically generate an electron-primed photocatalyst, albeit one that did not possess reduction potentials more negative than $-2 \mathrm{~V} v$ s. SCE. ${ }^{[28]}$ The conPET strategy requires a carefully balanced system; both catalyst oxidation states must engage in excited state intermolecular SET under a single set of reaction conditions. ${ }^{[20]}$ Additionally, the byproducts of catalyst activation, which are typically reactive amine radical cations and easily reduced iminium ions, must not deactivate the catalyst or interfere in subsequent steps. ${ }^{[29]}$ These fundamental challenges associated with catalyst generation and turnover have resulted in only a small collection of electron-primed photocatalytic systems being identified in the subsequent years ${ }^{[28,30]}$ despite photophysical studies establishing that numerous persistent organic radical anions absorb visible light. ${ }^{[31-35]}$
We envisioned that electrochemistry ${ }^{[36]-[37]}$ would offer a flexible approach to generate electron-primed photoredox catalysts as cathodic reduction is highly tunable and divided cell electrolysis excludes interfering oxidized byproducts. Indeed, we previously used this approach to introduce a novel electron-primed photocatalyst capable of reducing aryl chloride substrates with $E_{\text {red }}$ more negative than $\mathrm{Li}^{0}{ }^{[27]}$

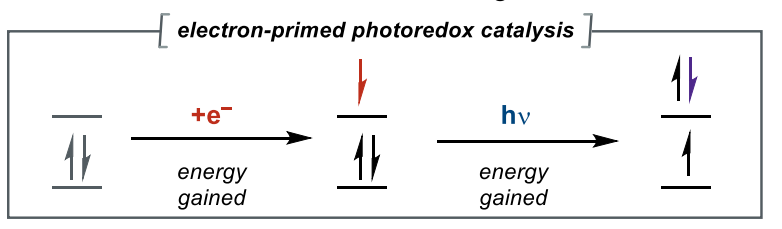

established electron-primed photocatalysts
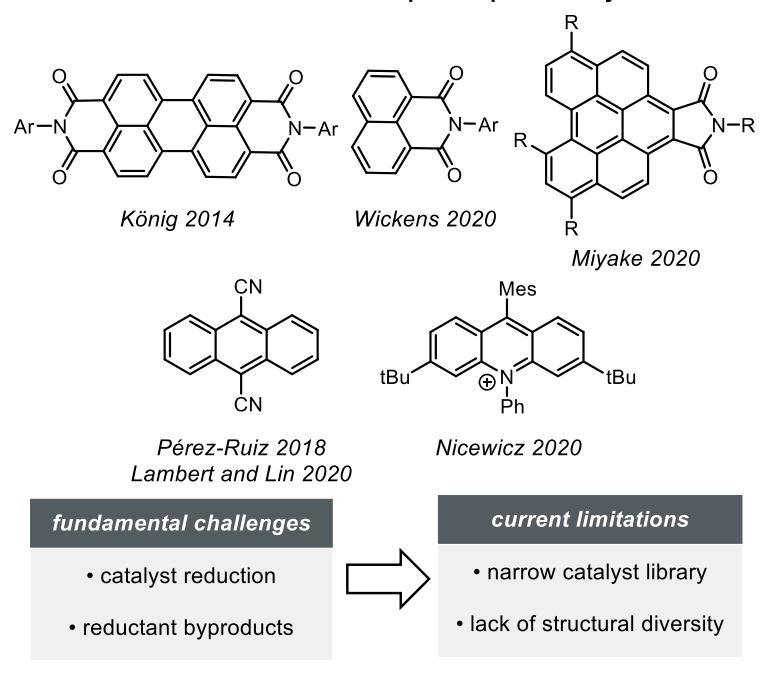

Electrochemistry-enabled discovery of radical anion photocatalysts

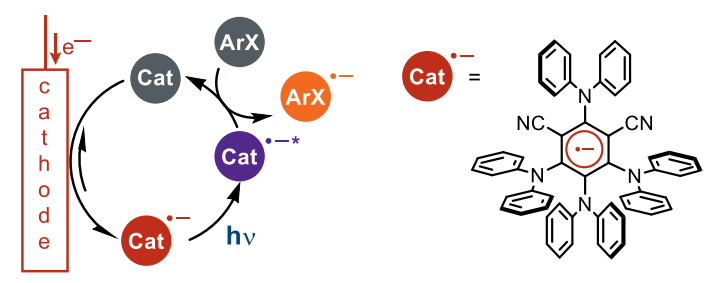

expanded library $\cdot$ cleavage of strong bonds $\cdot$ improved stability

Figure 1: (top) established catalysts known to promote SET redox events through electron-primed photoredox catalysis and (bottom) electrochemically driven electron-primed photoredox catalysis and a new catalyst discovered in this work derived from 4-DPAIPN. 
Contemporaneous efforts by Lambert and Lin disclosed that 9,10-dicyanoanthracene, an electron-primed photoredox catalyst previously accessed via conPET, ${ }^{[30]}$ exhibits enhanced reactivity towards aryl chloride substrates when driven electrochemically. ${ }^{[26]}$ However, while these two discoveries validated the use of electrochemistry to generate potent photoreductants, both of these electrophotocatalysts remained structurally analogous to established conPET-based photocatalysts. Furthermore, while rapid progress has been made in electrophotocatalytic oxidations, ${ }^{[38-42]}$ electrophotocatalytic reductions remain underdeveloped. Herein, we employ cathodic reduction to illustrate that numerous persistent radical anions act as catalytic photoreductants and reveal a new electron-primed photoredox catalyst that enables cleavage of strong $\mathrm{C}\left(\mathrm{sp}^{2}\right)-\mathrm{N}$ and $\mathrm{C}\left(\mathrm{sp}^{2}\right)_{-}$ $O$ bonds.

The generation of aryl radical intermediates is a wellestablished arena to benchmark new photoreductants. Benchstable $^{[43-46]}$ trialkylanilinium salts and activated phenols are readily accessible and can be reductively cleaved to aryl radical intermediates through deeply reducing direct electrolysis or alkali metal reductants, however, they remain difficult to activate under photocatalytic conditions. ${ }^{[47,48]}$ Within the past year, Larionov and König illustrated that anilide and thiolate photocatalysts are capable of promoting the borylation of anilinium salts and activated phenols via photoreduction. ${ }^{[49,50]}$ However, examples of photochemical net-reductive processes remain limited. Reductive defunctionalization is used as a synthetic tactic to leverage aniline and phenol activating groups in a traceless manner. ${ }^{[51-}$
54] Current methods to remove these directing groups rely on harsh dissolving metal conditions ${ }^{[55,56]}$ or palladium catalysis. ${ }^{[57,58]}$ We envisioned that cleavage of these strong bonds was a perfect arena to explore new potent reductants given recently reported halogen-atom transfer strategies, which in some cases can circumvent deeply reducing potentials, ${ }^{[59]}$ are unlikely to be amenable to the cleavage of these less polarizable heteroatoms. ${ }^{[60,61]}$

We initiated our studies with the reductive cleavage of an $N, N, N$-trimethyl anilinium salt, 1 (Table 1). We anticipated that the thermodynamic and kinetic challenges presented by aryl $\mathrm{C}\left(\mathrm{sp}^{2}\right) \mathrm{N}$ bond cleavage would expose the limitations of current electron-primed photocatalysts. We found that NpMI, the electron-primed photoredox catalyst we recently reported, ${ }^{[27]}$ could cleave the $\mathrm{C}\left(\mathrm{sp}^{2}\right)-\mathrm{N}$ bond in $42 \%$ yield under a constant cathodic potential and visible light irradiation. This result validated that an electron-primed photoredox system is capable of engaging this substrate but also highlighted the need for improved catalysts.

We next evaluated a collection of structures related to the NpMI core. Electrochemistry facilitated rapid catalyst evaluation in two primary ways: (1) cyclic voltammetry studies established the minimum cathodic potential to generate the radical anion photocatalyst and (2) evaluation of wavelength dependent photocurrent established optimal irradiation wavelength (see SI for details). ${ }^{[62]}$ These studies revealed that various derivatives of $\mathbf{N p M I}$ including $\mathrm{NpDI}$, PMI, and Nplmz each provided the defunctionalized product, albeit in reduced yield relative to NpMI. Given these data, we concluded that a

Table 1: Evaluation of Electrochemically-Generated Persistant Radical Anions for Photocatalytic Activity ${ }^{a, b}$

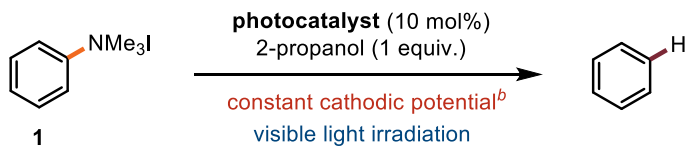

imide-based persistent radical anions
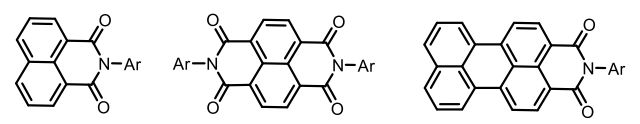

$\begin{array}{cc}\text { NpMI }^{c} & \text { NpDI }^{c} \\ E_{\text {red }}=-1.3 \mathrm{~V} & E_{\text {red }}=-0.4 \mathrm{~V} \\ 405 \mathrm{~nm} & 390 \mathrm{~nm} \\ 42 \% & 11 \%\end{array}$

metal-based scaffolds

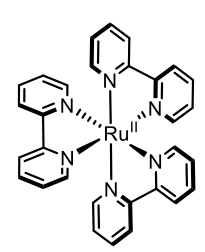

$\mathrm{Ru}(\mathrm{bpy})_{3}(\mathbf{R u}-1)$

$E_{\text {red }}=-1.3 \mathrm{~V}$

$427 \mathrm{~nm}$

$9 \%$

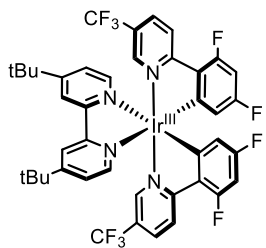

$\operatorname{Ir}\left(\mathrm{dF}-\mathrm{CF}_{3}-\mathrm{ppy}\right)_{2}(\mathrm{dtbpy})^{d}$ । (Ir-1)

$E_{\text {red }}=-1.4 \mathrm{~V}$

$427 \mathrm{~nm}$

$30 \%$ isophthalonitrile scaffolds

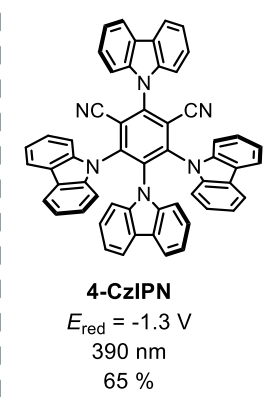

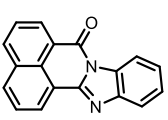

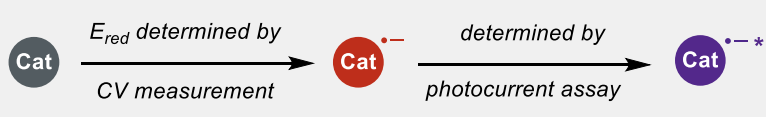

persistent organic radical anions
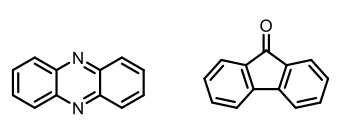<smiles>O=C(O)c1ccccc1-c1c2ccc(=O)cc-2oc2cc(O)ccc12</smiles><smiles>O=C1c2ccccc2C(=O)c2ccccc21</smiles>

$$
\begin{array}{cc}
\mathbf{P Z} & \mathbf{F L} \\
E_{\text {red }}=-1.2 \vee & E_{\text {red }}=-1.3 \\
440 \mathrm{~nm} & 405 \mathrm{~nm} \\
36 \% & 45 \%
\end{array}
$$

FC

$E_{\text {red }}=-1.2 \mathrm{~V}$

$405 \mathrm{~nm}$

$34 \%$

AQ

$405 \mathrm{~nm}$

$405 \mathrm{~nm}$
$41 \%$

$45 \%$

$E_{\text {red }}=-0.9$

$405 \mathrm{~nm}$

$10 \%$

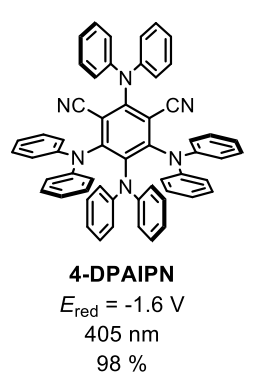

photoactivity of diverse radical anions

100

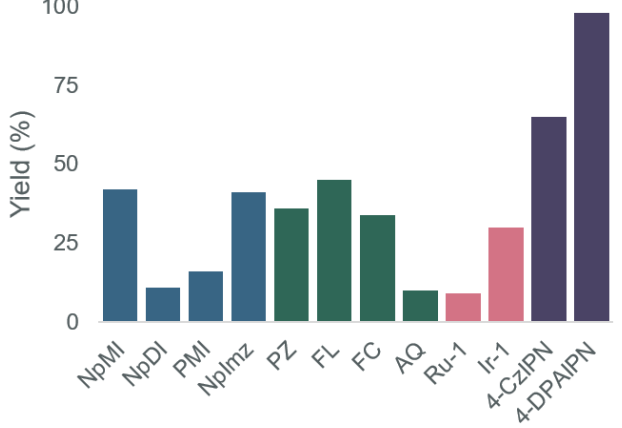

${ }^{a}$ Reactions were conducted on a $0.2 \mathrm{mmol}$ scale in $\mathrm{DMF}\left(0.1 \mathrm{M} \mathrm{Bu}_{4} \mathrm{NPF}_{6}\right)$ with RVC cathode and anode. Reaction were run for 12 hours. ${ }^{b}$ all redox potentials reported relative to SCE. ${ }^{c} \mathrm{Ar}=2,6$-diisopropylphenyl. ${ }^{d}$ Reaction was conducted with $1 \mathrm{~mol} \%$ catalyst. See the supporting information (SI) for further details. 
fundamentally different catalyst scaffold was likely necessary to efficiently promote these challenging reductions.

We next targeted more structurally diverse persistent radical anion precursors that have not been explored as electron-primed photocatalysts. ${ }^{[35,63-66]}$ We found that the radical anion congeners of phenazine, fluorenone, and fluorescein each promote reduction of $\mathbf{1}$ in comparable yields to NpMI under appropriate electrophotocatalytic conditions. Control reactions revealed that no conversion is observed in the absence of electrolysis indicating that the photoactivity of the neutral structures is insufficient to drive defunctionalization of 1. These data suggest that electrochemical reduction can coax potent photocatalytic activity out of a much broader range of molecules than previously appreciated. Next, we recognized that nearly all photoredox catalysts, by design, undergo reversible redox events and many possess persistent radical anion congeners. ${ }^{[6,10,67]}$ We questioned whether the structural features that render molecules effective as conventional photoredox catalysts would translate to the electron-primed photoredox manifold. ${ }^{[68,24,69]}$ Intriguingly, we found that electrolysis at the $E_{\text {red }}$ of several commonly employed photoredox catalysts $\left(\mathrm{Ru}(\mathrm{bpy})_{3},{ }^{[70]} \operatorname{Ir}\left(\mathrm{dF}-\mathrm{CF}_{3}-\mathrm{ppy}\right)_{2}(\mathrm{dtbpy}),{ }^{[70]}\right.$ and 4-CzIPN ${ }^{[71]}$ turned on photocatalytic activity in this challenging reduction. ${ }^{[72]}$ While there is a sole report proposing photochemical activity of the reduced congener of an Ir-based photoredox catalyst, ${ }^{[73]}$ these are the first data consistent with either Ru-based or isophthalonitrile structures acting as electron-primed photoredox catalysts. Given that cathodic reduction of 4-CzIPN resulted in a meaningful improvement in photochemical deamination yield, we examined other isothphalonitrile catalysts. This investigation revealed that 4DPAIPN $^{[74]}$ promotes the reduction of model substrate $\mathbf{1}$ in nearly quantitative yield under electrophotocatalytic conditions.
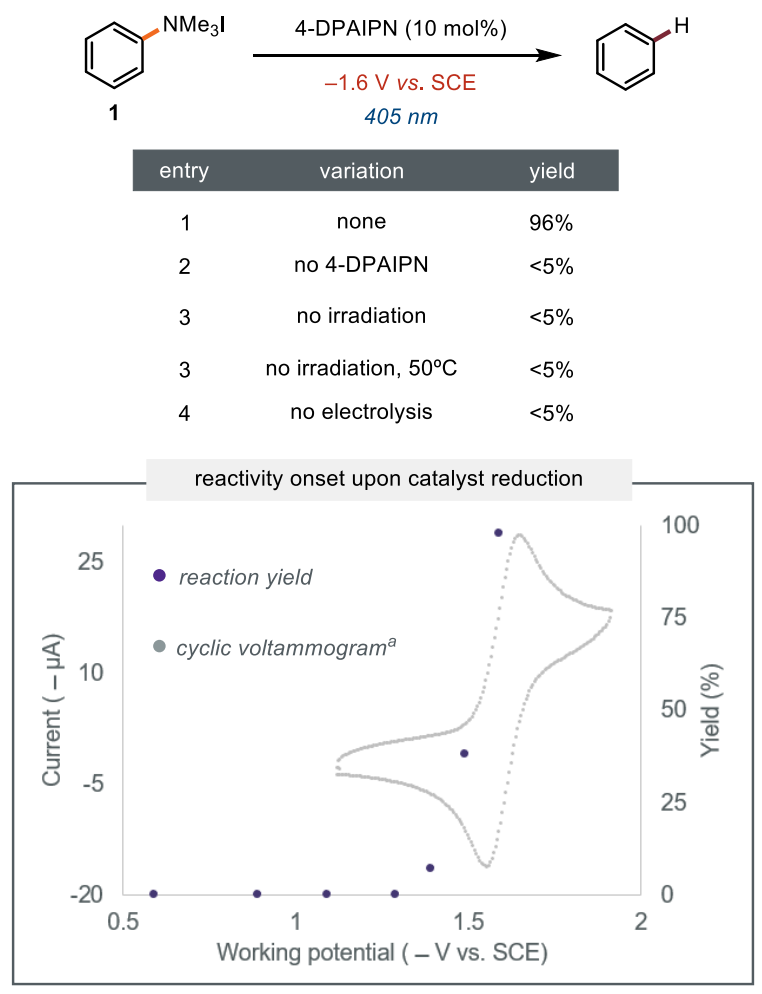

Figure 2: Reactions were conducted on a $0.2 \mathrm{mmol}$ scale in DMF $(0.1 \mathrm{M}$ $\mathrm{Bu}_{4} \mathrm{NPF}_{6}$ ) and run for 12 hours. ${ }^{\mathrm{a}} \mathrm{CV}$ is of 4-DPAIPN. See Supporting Information (SI) for more details.
Additional control reactions similarly revealed no conversion of 1 when electrolysis and irradiation were not applied to each catalyst simultaneously. Overall, the structural diversity of the potent photocatalysts identified through these studies suggest that photoactivity of persistent radical anions is a general phenomenon and provide a clear link between precise catalyst structure and reaction outcome.

We next evaluated whether 4-DPAIPN was promoting this reaction via excitation of its radical anion congener. Under electrochemical stimulation 4-DPAIPN acts as a far more potent photoreductant than anticipated by its established redox potentials $\left(\mathrm{E}_{1 / 2} \mathrm{PC}^{+} / \mathrm{PC}^{*}\right)=-1.3 \mathrm{~V}$ and $\mathrm{E}_{1 / 2}\left(\mathrm{PC} / \mathrm{PC}^{-}\right)=-1.5 \mathrm{~V}$ vs $S C E)^{[74]}$ (Figure 2). First, we conducted a series of control experiments and found that catalyst, electrolysis, and light were all required for product formation. Next, we measured the defunctionalization yield at varied cathodic potentials. Overlaying these data with the cyclic voltammogram of 4DPAIPN illustrates that reactivity is observed only when a sufficient potential to reduce 4-DPAIPN is applied. These data are fully consistent with cathodic catalyst reduction and subsequent excitation as necessary steps for this difficult reductive transformation.

We next probed the scope of this catalytic $\mathrm{C}\left(\mathrm{sp}^{2}\right)-\mathrm{N}$ cleavage process. We found ethers (3), free alcohols (4), esters (5), and amides (6) as well as heterocycles such as piperazine (6), pyrrolidine (7), and morpholine (8) were all welltolerated. Notably, this reaction enables a molecular editing strategy wherein an $\mathrm{N}$-aryl ring can be replaced by an alkyl group through an alkylation/reductive cleavage sequence (10) as both aryl and amine fragments can be recovered after $\mathrm{C}\left(\mathrm{sp}^{2}\right)-\mathrm{N}$ reduction. Given the promising activity of this catalytic system in the cleavage of anilinium salts, we turned our attention to more difficult to reduce $\mathrm{C}\left(\mathrm{sp}^{2}\right)-\mathrm{O}$ bonds. Phenol derivatives (e.g. triflates and phosphates) possess deep reduction potentials (typically $<-2.7 \mathrm{~V}$ vs. SCE) and are resistant to fragmentation due to the strong $\mathrm{C}\left(\mathrm{sp}^{2}\right)-\mathrm{O}$ bond $(B D E=118 \mathrm{kcal} / \mathrm{mol}) .{ }^{[75-78]}$ Despite the energetic demands of $\mathrm{C}\left(\mathrm{sp}^{2}\right)-\mathrm{O}$ cleavage, phosphate ester substrates bearing a range of functional groups such as esters (11), amides (13), ethers (14), benzylic amines (15), unprotected alcohols and tertiary amines (17) as well as heterocycles such as imidazole (16) and piperazine (18) each underwent productive $\mathrm{C}\left(\mathrm{sp}^{2}\right)-\mathrm{O}$ cleavage. While each of these reactions are conducted far below the cathodic potential required to reduce the substrate, we questioned whether deeply reducing electrolysis could recapitulate this electrophotocatalytic activity. To probe this, we carried out direct electrolysis reactions on two substrates bearing functional groups to investigate the role of the catalyst in preserving chemoselectivity. Under constant current conditions in the absence of catalyst, 15 and 18 showed significant conversion to an intractable mixture containing $<20 \%$ product. By promoting reduction through a photocatalytic mediator under mild electrochemical potentials, chemoselectivity and functional group tolerance can be vastly improved compared to direct electrolysis conditions.

Phenols are electron-donating groups that enable a wide range of reactions at the arene core. ${ }^{[79-83]}$ We envisioned that the scope of products accessible using these processes could be expanded through a chemoselective excision of the phenolic activating group via an electrophocatalytic system (Figure 3). For example, this strategy allows selective formation of meta-substituted products inaccessible via direct 
Table 2: Scope of Aryl $C\left(s p^{2}\right)-N$ and $C\left(s p^{2}\right)-O$ bond cleavage ${ }^{a}$

$$
\underset{\substack{0.1 .6 \mathrm{M} \text { vs SCE } \\ 405 \mathrm{~nm}}}{\substack{\mathrm{M} \mathrm{Bu}_{4} \mathrm{NPF}_{6}, \mathrm{DMF} \\ \text { 4-DPAIPN (10 mol \%) }}}
$$

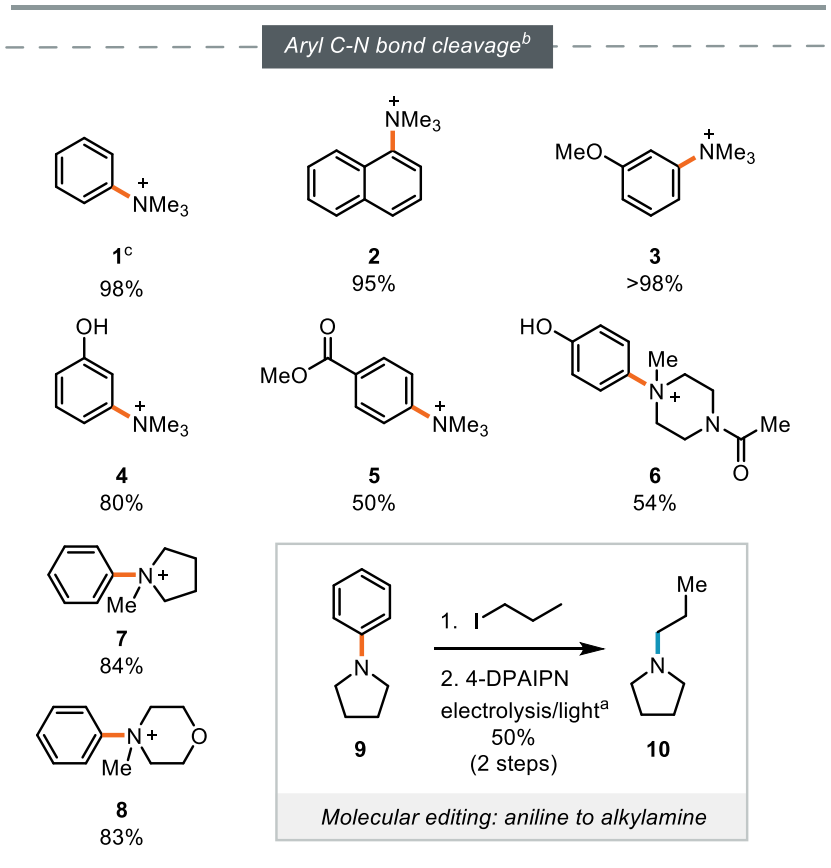

Aryl C-O bond cleavage
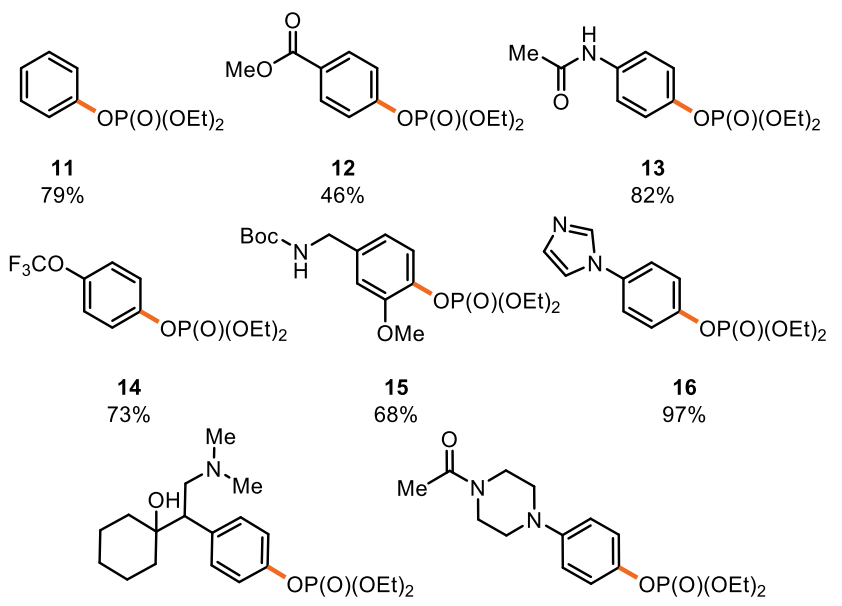

Desvenlafaxine phosphate

$$
\begin{array}{lc}
17 & 18 \\
59 \% & 80 \%
\end{array}
$$

${ }^{a}$ Reactions were conducted on a $0.2 \mathrm{mmol}$ scale and run for $12 \mathrm{~h}$ in a divided cell with RVC electrodes. $\mathrm{Et}_{3} \mathrm{~N}$ ( 2 equiv) was added to the anodic chamber as a terminal reductant. ${ }^{b}$ The counter ion is OTf unless otherwise noted. ${ }^{c} \mathbf{1}$ used as the iodide salt. See the SI for experimental details.

Friedel-Crafts reactions. ${ }^{[84]}$ To illustrate this strategy, we prepared a suite of meta-substituted arene products from simple precursors using a phenol-directed alkylationdefunctionalization sequence (19-22). As a direct comparison, we subjected 22 to constant current conditions in the absence of catalyst and observed high conversion with substantially diminished yield. To demonstrate the value of a phenoldirected alkylation-defunctionalization approach, we targeted the synthesis of a tricyclic resorcinol derivative that was developed as a conformationally restricted cannabinoid
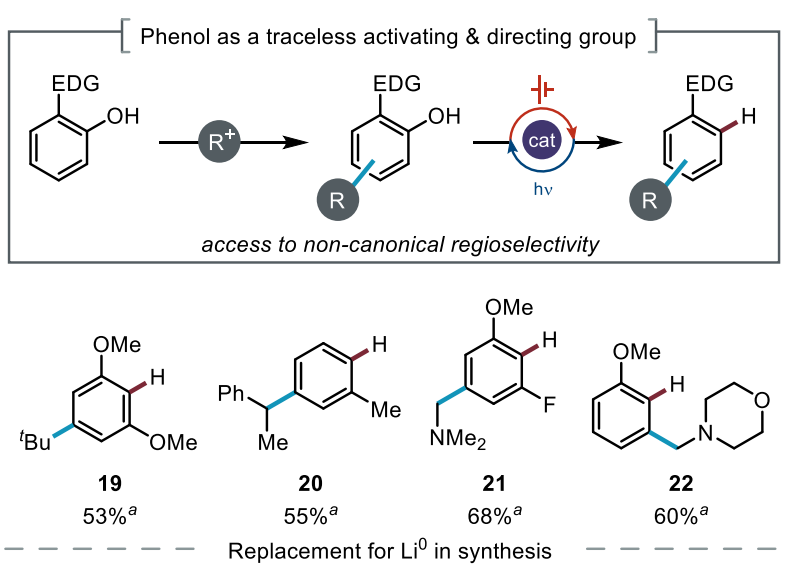<smiles>COc1cccc(OC)c1O</smiles>

syringol

$( \pm)-23$

$E_{\text {red }}=-3.54 \mathrm{~V}$ vs SCE

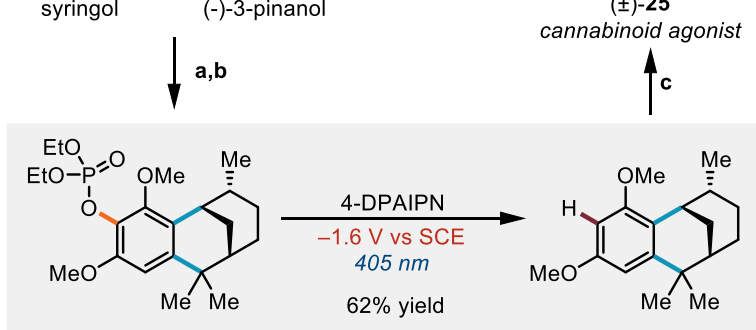

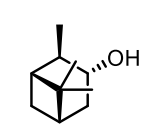

(-)-3-pinanol

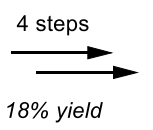

$18 \%$ yield

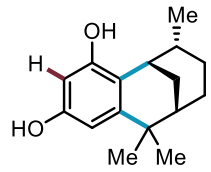

$( \pm)-25$

cannabinoid agonist
$( \pm)-24$

Figure 3: Phenol as a traceless directing group enabled by electronprimed photoredox catalysis. ${ }^{a}$ Yields reported are for the phosphate defunctionalization step. (a) $70 \%$ aq $\mathrm{MeSO}_{3} \mathrm{H}, 70{ }^{\circ} \mathrm{C}, 12 \mathrm{~h}(45 \%$ yield). (b) $\mathrm{CIP}(\mathrm{O})(\mathrm{OEt})_{2}, \mathrm{DABCO}, \mathrm{MeCN}, 18 \mathrm{~h}\left(70 \%\right.$ yield). (c) $\mathrm{BBr}_{3}, \mathrm{DCM},-78^{\circ} \mathrm{C}$, $12 \mathrm{~h},(91 \%$ yield). Conversion of $\mathbf{2 3}$ to 24 was accomplished under conditions analogous to those in Table 2. See SI for experimental details.

agonist. The route, devised by Makriyannis, ${ }^{[85]}$ hinged on phenol-enabled Friedel-Crafts alkylation followed by a $\mathrm{Li}^{0}$ promoted excision of the phenol activating group. In our hands, the Friedel-Crafts process and subsequent phosphorylation proceeded smoothly to deliver tricyclic intermediate 23. Gratifyingly, electron-primed photoredox $\mathrm{C}\left(\mathrm{sp}^{2}\right)-\mathrm{O}$ cleavage furnished intermediate $\mathbf{2 4}$ despite a nearly $2 \mathrm{~V}$ underpotential supplied at the cathode. Global demethylation furnished 25 in $18 \%$ yield over 4 steps. These data demonstrate how this new catalytic platform can directly fit into synthetic sequences and circumvent the need for more hazardous chemical reductants in the preparation of complex biologically active molecules.

Having established that 4-DPAIPN is a broadly effective electron-primed photoredox catalyst with immediate synthetic utility, we next aimed to understand the origin of the improved performance of 4-DPAIPN relative to prior electron-primed photoredox catalysts. Specifically, we questioned whether 4DPAIPN possessed enhanced reactivity, superior catalyst stability, ${ }^{[86]}$ or both. To address this question, we envisioned that electrochemical current could be employed as a noninvasive in situ rate monitoring technique to unlock tools from reaction progress kinetic analysis (RPKA). ${ }^{[87]}$ This method can reveal phenomena such as catalyst decomposition and product inhibition typically invisible to classic initial rate kinetics because the analysis is conducted under typical preparative conditions. We conducted a "same excess" experiment with 
both our previously reported electron-primed photocatalyst, NpMI, and 4-DPAIPN to compare the extent of catalyst deactivation in each case. We selected aryl chloride $\mathbf{2 6}$ as the model substrate because both catalysts can engage this substrate under constant potential conditions and preliminary investigations indicated it exhibited a well-behaved kinetic profile. ${ }^{[88,89]}$ We carried out two separate constant potential experiments for $\mathbf{N p M I}$ at different initial concentrations of 26 (traces $a$ and $b$ ). When rate is plotted as a function of [26], the two curves do not overlay. This indicates either catalyst death or product inhibition. Inhibition by the arene product was excluded by addition of $\mathbf{2 7}$, which did not restore overlay between the curves. Furthermore, NpMI exhibited an unusual kinetic profile consistent with decomposition into a new catalytically active species that subsequently decomposes. These data implicate rapid deactivation of NpMI under these conditions. In stark contrast, analogous "same excess" experiment with 4-DPAIPN resulted in clean first order reaction profiles that nearly overlay. These data are consistent with turnover limiting photoreduction of $\mathbf{2 6}$ and minimal catalyst decomposition or product inhibition (see SI for details). As with $\mathbf{N p M I}$, addition of $\mathbf{2 7}$ excluded product inhibition and suggests catalyst decomposition occurs but is dramatically attenuated relative to $\mathrm{NpMI}$. These data indicate that the improved performance of 4-DPAIPN can be attributed to it forming a more robust electron-primed photoredox catalyst. Indeed, the initial rate of dehalogenation promoted by $\mathbf{N p M I}$ is faster than 4-DPAIPN but rapid decomposition of this catalyst renders it
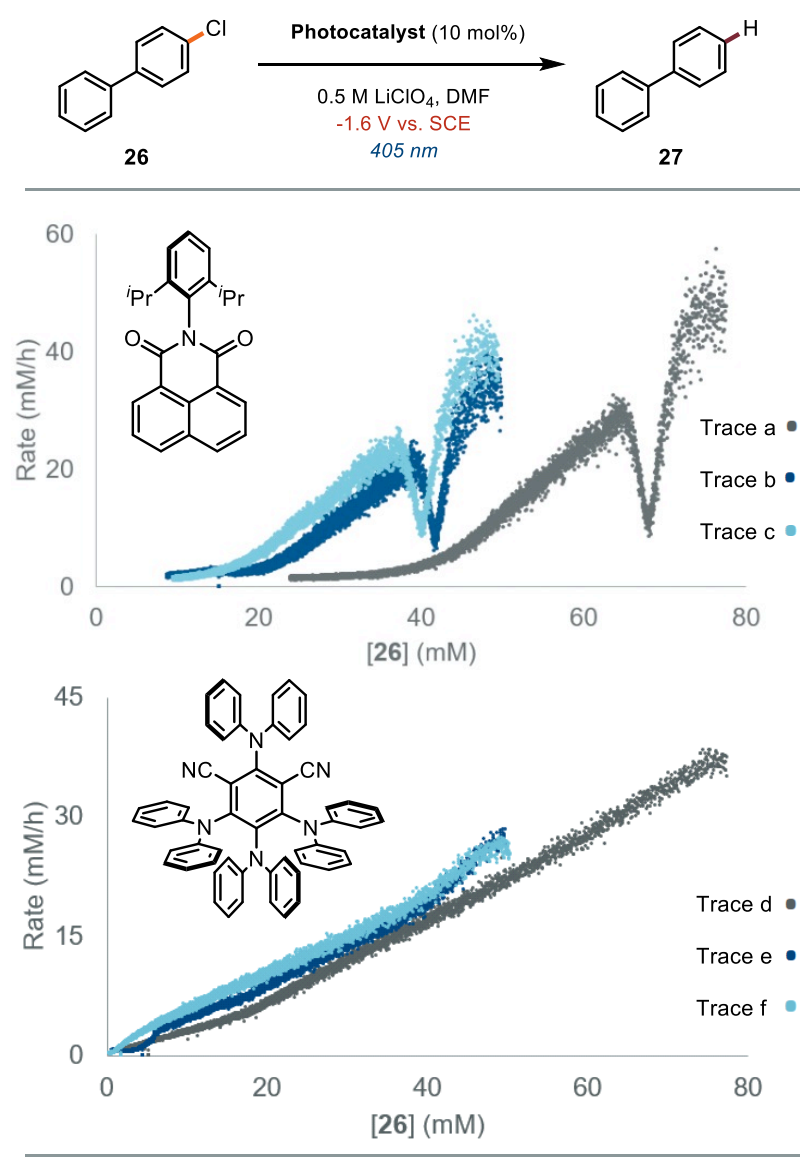

Figure 4: Reactions performed on a $0.4 \mathrm{mmol}$ scale. Trace a and $\mathrm{d}$ : $[\mathrm{ArCl}]_{0}$ $=0.08 \mathrm{M}$ (standard reaction concentration), Trace $\mathrm{b}$ and $\mathrm{e}:[\mathrm{ArCl}]_{0}=0.052$ $\mathrm{M}$, Trace $\mathrm{c}$ and $\mathrm{f}:[\mathrm{ArCl}]_{0}=0.052 \mathrm{M},[\mathrm{ArH}]_{0}=0.028 \mathrm{M}$. See the SI for details ineffective for more challenging substrates that are slower to fragment following reduction.

Overall, we have demonstrated that electrochemistry is an effective tool to explore structurally diverse electron-primed photoredox catalysts. These investigations revealed that numerous persistent radical anions exhibit catalytic photoreductant behavior and uncovered that the radical anion congener of a common photoredox catalyst, 4-DPAIPN, is an exceptionally potent photoreductant. This discovery enabled a new catalytic system to promote the reductive cleavage of diverse $\mathrm{C}\left(\mathrm{sp}^{2}\right)-\mathrm{N}$ and $\mathrm{C}\left(\mathrm{sp}^{2}\right)-\mathrm{O}$ bonds, which we anticipate will enable an array of synthetic sequences that previously would have mandated alkali metal reductants. Finally, we illustrated how principles from RPKA could be directly employed in electrophotocatalysis, using electrochemical current to monitor reaction rate in situ throughout a reaction. We anticipate radical anions will serve as a structurally diverse family of photoredox catalysts for challenging reductive processes and that these studies will provide a roadmap for the use of electrochemistry to both drive and interrogate such systems.

\section{Acknowledgements}

We thank Prof. Alison Wendlandt for helpful suggestions. We thank the entire Stahl lab for their assistance in use of spectroelectrochemical equipment. Additionally, we thank the Stahl, Weix, Yoon, and Schomaker groups for sharing their chemical inventory. Tracy Drier is acknowledged for electrochemical glassware fabrication. This work was financially supported by the Office of the Vice Chancellor for Research and Graduate Education at the University of Wisconsin-Madison with funding from the Wisconsin Alumni Research Foundation. This material is based upon work supported by the National Science Foundation under Grant No. (2047108). Acknowledgment is made to the Donors of the American Chemical Society Petroleum Research Fund for partial funding of this research (60677-DNI1). Spectroscopic instrumentation was supported by a generous gift from Paul. J. and Margaret M. Bender, NSF (CHE-1048642), and NIH (1S10 OD020022-1).

\section{References}

E. C. Ashby, Acc. Chem. Res. 1988, 21, 414-421.

[2] N. Zhang, S. R. Samanta, B. M. Rosen, V. Percec, Chem. Rev. 2014, 114, 5848-5958.

[3] J. Broggi, T. Terme, P. Vanelle, Angew. Chem. Int. Ed. 2014, 53, 384-413.

[4] L. Eberson, in Advances in Physical Organic Chemistry (Eds.: V. Gold, D. Bethell), Academic Press, 1982, pp. 79-185.

[5] C. K. Prier, D. A. Rankic, D. W. C. MacMillan, Chem. Rev. 2013, 113, 5322-5363.

[6] M. H. Shaw, J. Twilton, D. W. C. MacMillan, J. Org. Chem. 2016, 81, 6898-6926.

[7] N. A. Romero, D. A. Nicewicz, Chem. Rev. 2016, 116, 1007510166.

[8] K. L. Skubi, T. R. Blum, T. P. Yoon, Chem. Rev. 2016, 116, 10035-10074.

[9] D. A. DiRocco, K. Dykstra, S. Krska, P. Vachal, D. V. Conway, M. Tudge, Angew. Chem. Int. Ed. 2014, 53, 4802-4806.

[10] J. M. R. Narayanam, C. R. J. Stephenson, Chem. Soc. Rev.
2010, 40, 102-113.

[10] J. M. R. Narayanam, C. R. J. Stephenson, Chem. Soc. Rev.
2010, 40, 102-113.

[11] D. M. Arias-Rotondo, J. K. McCusker, Chem. Soc. Rev. 2016 , 
K. K. Kundu, A. K. Rakshit, M. N. Das, Electrochimica Acta 1972 , 17, 1921-1937.

H. G. Roth, N. A. Romero, D. A. Nicewicz, Synlett 2016, 27, 714723.

K. V. Chuang, C. Xu, S. E. Reisman, Science 2016, 353, 912915.

C. He, T. P. Stratton, P. S. Baran, J. Am. Chem. Soc. 2019, 141, 29-32.

D. K. Joshi, J. W. Sutton, S. Carver, J. P. Blanchard, Org. Process Res. Dev. 2005, 9, 997-1002.

E. Speckmeier, T. G. Fischer, K. Zeitler, J. Am. Chem. Soc. 2018, 140, 15353-15365.

A. Joshi-Pangu, F. Lévesque, H. G. Roth, S. F. Oliver, L.-C. Campeau, D. Nicewicz, D. A. DiRocco, J. Org. Chem. 2016, 81, 7244-7249.

B. K. Peters, K. X. Rodriguez, S. H. Reisberg, S. B. Beil, D. P. Hickey, Y. Kawamata, M. Collins, J. Starr, L. Chen, S. Udyavara, K. Klunder, T. J. Gorey, S. L. Anderson, M. Neurock, S. D. Minteer, P. S. Baran, Science 2019, 363, 838-845.

F. Glaser, C. Kerzig, O. S. Wenger, Angew. Chem. Int. Ed. 2020, 59, 10266-10284.

T. U. Connell, C. L. Fraser, M. L. Czyz, Z. M. Smith, D. J. Hayne, E. H. Doeven, J. Agugiaro, D. J. D. Wilson, J. L. Adcock, A. D. Scully, D. E. Gómez, N. W. Barnett, A. Polyzos, P. S. Francis, J. Am. Chem. Soc. 2019, 13.

J.-H. Shon, D. Kim, M. D. Rathnayake, S. Sittel, J. Weaver, T. S. Teets, Chem. Sci. 2021, 12, 4069-4078.

C. Kerzig, X. Guo, O. S. Wenger, J. Am. Chem. Soc. 2019, 141 , 2122-2127.

I. A. MacKenzie, L. Wang, N. P. R. Onuska, O. F. Williams, K. Begam, A. M. Moran, B. D. Dunietz, D. A. Nicewicz, Nature 2020, 580, 76-80.

J. P. Cole, D.-F. Chen, M. Kudisch, R. M. Pearson, C.-H. Lim, G. M. Miyake, J. Am. Chem. Soc. 2020, 142, 13573-13581. H. Kim, H. Kim, T. H. Lambert, S. Lin, J. Am. Chem. Soc. 2020, 142, 2087-2092.

N. G. W. Cowper, C. P. Chernowsky, O. P. Williams, Z. K. Wickens, J. Am. Chem. Soc. 2020, DOI 10.1021/jacs.9b12328. I. Ghosh, T. Ghosh, J. I. Bardagi, B. Konig, Science 2014, 346, 725-728.

$\mathrm{Et}_{3} \mathrm{~N}$ can promote premature radical quenching through hydrogen atom transfer and back electron transfer to $\mathrm{Et}_{3} \mathrm{~N} \cdot+$ For details see ref [7]

M. Neumeier, D. Sampedro, M. Májek, V. A. de la Peña O'Shea, A. Jacobi von Wangelin, R. Pérez-Ruiz, Chem. Eur. J., 2018, 24, 105-108.

D. Gosztola, M. P. Niemczyk, W. Svec, A. S. Lukas, M. R. Wasielewski, J. Phys. Chem. A 2000, 104, 6545-6551. M. Fujitsuka, S. S. Kim, C. Lu, S. Tojo, T. Majima, J. Phys. Chem. B 2015, 119, 7275-7282.

H. Nakashima, T. Shida, H. Nakatsuji, J. Chem. Phys. 2012, $136,214306$.

N. T. La Porte, J. F. Martinez, S. Chaudhuri, S. Hedström, V. S. Batista, M. R. Wasielewski, Coord. Chem. Rev., 2018, 361, 98119.

M. Anne. Fox, Chem. Rev. 1979, 79, 253-273.

R. Francke, R. D. Little, Chem. Soc. Rev. 2014, 43, 2492-2521. T. H. Meyer, L. H. Finger, P. Gandeepan, L. Ackermann, Trends in Chemistry 2019, 1, 63-76.

H. Huang, T. H. Lambert, Angew. Chem. Int. Ed.., Early View, DOI https://doi.org/10.1002/anie.202100222.

H. Huang, T. H. Lambert, Angew. Chem. Int. Ed., 2020, 59, 658662.

H. Huang, Z. M. Strater, M. Rauch, J. Shee, T. J. Sisto, C. Nuckolls, T. H. Lambert, Angew. Chem. Int. Ed., 2019, 58, 13318-13322.

H. Huang, Z. M. Strater, T. H. Lambert, J. Am. Chem. Soc. 2020, 142, 1698-1703.

H. Yan, Z.-W. Hou, H.-C. Xu, Angew. Chem. Int. Ed. 2019, 58, 4592-4595.

Aniline substrates can be converted into diazonium salts, which readily undergo reductive fragmentation to aryl radical intermediates. However, these salts explosive and the conditions to generate them are highly oxidizing. For more information, see [44], [45], [46].

N. Oger, E. L. Grognec, F.-X. Felpin, Org. Chem. Front. 2015, 2, 590-614.

P. Chakma, Z. A. Digby, M. P. Shulman, L. R. Kuhn, C. N. Morley, J. L. Sparks, D. Konkolewicz, ACS Macro Lett. 2019, 8 , 95-100.

J. B. Washington, Chem. Sci. 2021, 15.

U. Azzena, T. Denurra, G. Melloni, E. Fenude, G. Rassu, J. Org. Chem. 1992, 57, 1444-1448.

H. Xu, B. Yu, H. Zhang, Y. Zhao, Z. Yang, J. Xu, B. Han, Z. Liu, Chem. Commun. 2015, 51, 12212-12215.
S. Jin, Hang. T. Dang, G. C. Haug, R. He, V. D. Nguyen, V. T. Nguyen, H. D. Arman, K. S. Schanze, O. V. Larionov, J. Am. Chem. Soc. 2020, 142, 1603-1613.

$\mathrm{S}$. Wang, H. Wang, B. Koenig, 2020, DOI 10.26434/chemrxiv.13298837.v1.

I. Kalvet, K. Deckers, I. Funes-Ardoiz, G. Magnin, T. Sperger, M. Kremer, F. Schoenebeck, Angew. Chem. Int. Ed. 2020, 59, 7721-7725.

R. I. Duclos, D. Lu, J. Guo, A. Makriyannis, Tetrahedron Lett. 2008, 49, 5587-5589.

A. Manmade, J. L. Marshall, R. A. Minns, H. Dalzell, R. K. Razdan, J. Org. Chem. 1982, 47, 1717-1721.

N. A. Paras, D. W. C. MacMillan, J. Am. Chem. Soc. 2002, 124, 7894-7895.

H. Aviv, R. Bar, M. Schickler, S. Amselem, United States Patent Application: 0040110827 - High Enantiomeric Purity Dexanabinol for Pharmaceutical Compositions, A1, 20040110827.

N. A. Paras, B. Simmons, D. W. C. MacMillan, Tetrahedron 2009, 65, 3232-3238.

A. W. G. Burgett, Q. Li, Q. Wei, P. G. Harran, Angew. Chem. Int Ed. 2003, 42, 4961-4966.

S. Kodama, Y. Hamashima, K. Nishide, M. Node, Angew. Chem. Int. Ed. 2004, 43, 2659-2661.

Since halogen atom transfer relies on bond strength and polarizability, the vast majority of examples involve organoiodide or organobromide substrates. For examples, see [52] and [53]. T. Constantin, M. Zanini, A. Regni, N. S. Sheikh, F. Juliá, D. Leonori, Science 2020, 367, 1021-1026.

T. Constantin, F. Juliá, N. S. Sheikh, D. Leonori, Chem. Sci. 2020, 11, 12822-12828.

C. Costentin, J. Fortage, M.-N. Collomb, J. Phys. Chem. Lett. 2020, 11, 6097-6104.

M. Fujita, A. Ishida, T. Majima, S. Takamuku, J. Phys. Chem. 1996, 100, 5382-5387.

R. G. Compton, B. A. Coles, M. B. G. Pilkington, J. Chem. Soc., Faraday Trans. 11988, 84, 4347

B. R. Eggins, P. K. J. Robertson, J. Chem. Soc., Faraday Trans. 1994, 90, 2249-2256.

M. Fujitsuka, T. Majima, Journal of Photochemistry and Photobiology C: Photochemistry Reviews 2018, 35, 25-37.

N. A. Romero, D. A. Nicewicz, Chem. Rev. 2016, 116, 1007510166.

Given recent work from Nicewicz [24] and our group [61] that suggested that the odd electron conger of two common photoredox catalysts was photocatalytically active, we hypothesized that photochemical activity of oxidized and reduced photocatalysts might be a more general phenomenon. K. Targos, O. P. Williams, Z. K. Wickens, J. Am. Chem. Soc. 2021, 143, 4125-4132.

T. Koike, M. Akita, Inorg. Chem. Front. 2014, 1, 562-576.

T.-Y. Shang, L.-H. Lu, Z. Cao, Y. Liu, W.-M. He, B. Yu, Chem.I Commun. 2019, 55, 5408-5419.

Ce also questioned whether these catalysts could act either directly as photoreductants or electrochemically mediate the transformation (without input of light). Given that the PC/PC.couple is more negative in each case than the PC*/PC.+ couple, we conducted control experiments with each catalyst in the dark and found none furnished defunctionalized product without irradiation.

M. Giedyk, R. Narobe, S. Weiß, D. Touraud, W. Kunz, B. König, Nat. Catal., 2020, 3, 40-47.

P.P. Singh, V. Srivastava, Org. Biomol. Chem. 2021, 19, 313321.

Y.-R. Luo, Comprehensive Handbook of Chemical Bond Energies, CRC Press, 2007.

While direct electrolysis at deeply reducing potentials or C(sp2)O homolysis via high energy UV light can rupture these bonds, these approaches remain limited. For examples, see [69] and [70].

A. M. Mfuh, J. D. Doyle, B. Chhetri, H. D. Arman, O. V. Larionov, J. Am. Chem. Soc. 2016, 138, 2985-2988.

W. Liu, X. Yang, Y. Gao, C.-J. Li, J. Am. Chem. Soc. 2017, 139 , 8621-8627.

N. O. Calloway, Chem. Rev. 1935, 17, 327-392.

F.F. Blicke, F. J. McCarty, J. Org. Chem. 1959, 24, 1061-1069. Y. Omura, Y. Taruno, Y. Irisa, M. Morimoto, H. Saimoto, Y. Shigemasa, Tetrahedron Lett. 2001, 42, 7273-7275.

G. D. Cuny, Tetrahedron Lett. 2004, 45, 5167-5170

Z. Huang, J.-P. Lumb, ACS Catal. 2019, 35.

R. M. Roberts, Friedel-Crafts Alkylation Chemistry: A Century of Discovery, M. Dekker, [1984] @1984, New York, 1984.

D. Lu, S. P. Nikas, X.-W. Han, D. A. Parrish, A. Makriyannis, Tetrahedron Lett. 2012, 3.

[87] D. G. Blackmond, Angew. Chem. Int. Ed. 2005, 44, 4302-4320. 
[88] Altering electrolyte identity to lithium perchlorate as well as increasing electrolyte concentration significantly improved reproducibility of current traces of both 4-DPAIPN and NpMI with little to no impact on substrate conversion or product yield.

[89] We validated that current correlated to reaction rate by comparing the reaction profiles obtained via aliquot-based GC measurements to the current readout. These data indicated that current was directly proportional to reaction rate but required a minor scalar correction factor for faradaic efficiency. See SI for details. 
Photocatalytic activity of diverse organic radical anions-rxi... (1.53 MiB) view on ChemRxiv • download file 
conventional

photocatalyst

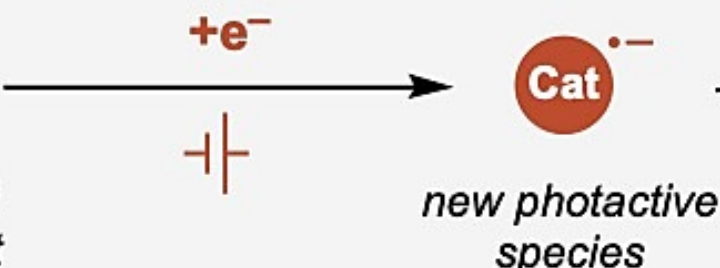

species

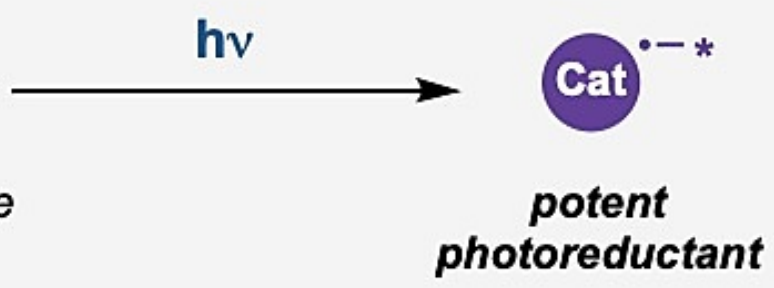

new photocatalytic reductants

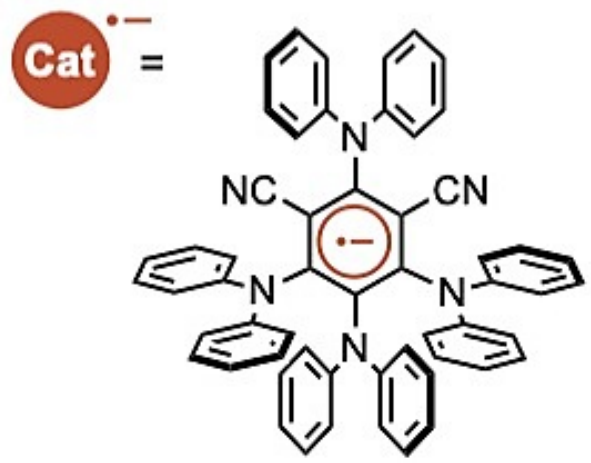

4-DPAIPN<smiles></smiles>

FL<smiles>c1ccc2nc3ccccc3nc2c1</smiles>

PZ cleavage of strong bonds<smiles>CN(C)c1ccccc1</smiles><smiles>CC(=O)N1CC[N+]([O-])(c2ccc(O)cc2)CC1</smiles>

Eto.<smiles>CCOP(=O)(OCC)Oc1c(OC)cc2c(c1OC)C1CCC(CC1C)C2(C)C</smiles><smiles>CCO[O+]Oc1ccccc1</smiles> 